\title{
Diagnostic firms discover key to profitability
}

ST.PAUL, Minn.-Out of the large universe of biotechnology companies vying for a slice of the $\$ 10$ billion market for diagnostic tests, most are finding that one or two successful products rarely make for a positive balance sheet. In fact, for the few firms that are profitable-including Quidel (San Diego, CA), Cambridge Biotech (Worcester, MA), Idexx (Westbrook, ME), Diagnostic Products (Los Angeles, CA), and Immucor (Norcross, GA)- the key seems to be developing a wide range of diagnostic tests that blanket one niche and then using that success to move into closely matched areas.

Quidel, for example, turned profitable last year, clearing $\$ 0.9$ million after losses of $\$ 5.5$ million and $\$ 6.8$ million in fiscal-year 1991 and 1990 , respectively, by honing in on the market for fertility and pregnancy tests. "With the technology we have, it is tempting to try to develop products for every major area of diagnostics, but we have focused on one small niche," says Scott Glenn, Quidel's chairman and chief executive officer (CEO). "The result is that we have captured 85 percent of the expanding market for fertility tests, and we are now moving aggressively into the related areas of pregnancy testing and vaginal-infection diagnostics."

\section{Competitive}

Idexx has chosen to avoid the predatory human health market and has found itself a niche in the smaller, but still profitable, market for veterinary diagnostics. "This is an underserved market that offers what I call razor and razor blade opportunities--reliable repeat business with the potential for consistent earnings over the long term," says David Shaw, Idexx's founder, president, and CEO. With over 75 products on the market, Idexx reported net earnings of $\$ 3.2$ million over the first nine months of 1992 , compared to $\$ 1.9$ million during the same period in 1991, the company's first profitable year.

The limited success that biotechnology firms are experiencing in the test-kit market is ironic, considering that biotechnology tools have revolutized the diagnostics industry. The new breed of biotechbased diagnostic tests are faster, cheaper, and more accurate than those that rely heavily on costly instrumentation. "The problem is that the diagnostics industry is intensely competitive and is characterized by rapid, dynamic change that can quickly turn a leader into a follower," explains Linda Miller, managing director of Paine Webber (Boston, MA). "It's a rare case where one successful product can change a company's fortunes."

Though Chiron (Emeryville, CA) hit the jackpot with its diagnostic for hepatitis C virus, Miller says that this $\$ 400$-million overnight success is a once-in-a-decade fluke. More typical, she says, is the experience of Cambridge Biotech, the first company to gain Food and Drug Administration (FDA, Bethesda, MD) approval for an AIDS diagnostic. The product was a success, but it failed to become a big money maker, because other products soon hit the market. As a result, product sales dropped 11.5 percent from 1989 to 1990 , and the company lost over \$10 million in fiscal 1990.

\section{Marketing strategles}

Cambridge Biotech has since returned to ranks of the profitable, thanks to a new management philosophy that broadened their product line to more thoroughly blanket the retrovirus diagnostic market. Today, the company not only sells its original HIV-1 overnight assay based on Westem blot technology, but also a two-hour Western blot test for HIV-2, a five-minute rapid AIDS test, two color-coded tenminute assays for HIV-1 and HIV2 , and the first PCR-based AIDS screening test approved by the FDA.

Through a series of strategic mergers and acquisitions, Cambridge Biotech has expanded its product line from nine to more than 60 diagnostics. Last year, for example, the company purchased a 17 percent stake in ADI Diagnostics (Toronto, Ont.) for \$3 million, with an option to acquire a majority interest in the company. This deal added tests for chlamydia, syphilis, and hepatitis to Cambridge Biotech's roster of diagnostics for sexually transmit- ted diseases.

Industry giants such as Becton Dickinson (FranklinLakes, NJ) and Abbott Laboratories (Abbott Park, IL) have the marketing resources that no biotechnology firm possesses, so the smaller companies have developed a variety of marketing strategies to survive. Cambridge Biotech, for example, has joined forces with Johnson \& Johnson subsidiary Ortho Diagnostic Systems (Raritan, NJ) to market its retroviral diagnostics to large users like hospitals and blood banks.

\section{R\&D}

Quidel, whose products are aimed less at hospitals and more at physicians, also has marketing agreements with Ortho Diagnostic, as well as with Becton Dickinson. But CEO Glenn says the company is moving away from such agreements and is marketing straight to the primary-care physician. "Our philosophy was to win over the primarycare doctors and have them be our in with the consumer. We started by marketing our ovulation test kits solely to the ob-gyn population and having the physician recommend our product by name to the patient," says Glenn.

As far as product development is concerned, the few profitable diagnostic firms seem to mix in-house research and development (R\&D) with selective product acquisitions through mergers and cooperative agreements. Idexx, for instance, actively seeks out academic and industrial partners who have done a significant amount of research but need help bringing a product to market. "We do tend to focus more on the development end than on research," says CEO Shaw.

At Quidel, the focus is more on inhouse discovery. "We really believe in our own staff, and we're not really interested in investing in someone else's R\&D," says Glenn. "We spend $\$ 4.5$ million to $\$ 5$ million a year on in-house R\&D and are confident that it will generate a new product every quarter. Where we'll invest in another company is if it improves our distribution capabilities and reduces our overhead significantly."

-Joseph Alper
For profitable

diagnostic

firms, the key

has been to

develop tests

that blanket

one niche

before moving into closely

related niches. 